\title{
Noise and Air Pollution Related to Health in Urban Environments ${ }^{\dagger}$
}

\author{
David Montes-González 1,*, Rosendo Vílchez-Gómez ${ }^{1}$, Juan Miguel Barrigón-Morillas ${ }^{1}$, \\ Pedro Atanasio-Moraga ${ }^{1}$, Guillermo Rey-Gozalo ${ }^{1,2}$ and José Trujillo-Carmona ${ }^{1}$ \\ 1 Department of Applied Physics, University of Extremadura, 10003 Cáceres, Spain; \\ vilchez@unex.es (R.V.-G.); barrigon@unex.es (J.M.B.-M.); pedroam@unex.es (P.A.-M.); \\ guille@unex.es (G.R.-G.); trujillo@unex.es (J.T.-C.) \\ 2 Facultad de Ciencias de la Salud, Universidad Autónoma de Chile, 3460000 Talca, Chile \\ * Correspondence: davidmg@unex.es; Tel.: +34-927-257-234 \\ + Presented at Environment, Green Technology and Engineering International Conference (EGTEIC 2018), \\ Caceres, Spain, 18-20 June 2018.
}

Published: 18 October 2018

\begin{abstract}
Environmental noise is a pollutant considered by the World Health Organization (WHO) as a threat to public health due to its harmful effects on human health. In this regard, the European Environmental Agency (EEA) indicates that road traffic is the sound source that generates the greatest number of people exposed in Europe to sound levels above what is recommended by the European Noise Directive. In a similar way, the EEA also reports that air pollution is the most important environmental health risk in Europe, where road traffic is one of the main sources of emission of polluting gases. The relationship between both pollutants, leads to think about the development of common strategies. This paper presents a review on recent researches about the relationship of these two types of pollution in urban environments with different types of diseases.
\end{abstract}

Keywords: noise pollution; air pollution; human health; urban environments; traffic noise

\section{Introduction}

World Health Organization (WHO) highlights in recent reports that environmental noise can be considered as a pollutant that has a significant impact on public health. This is due to the existence of evidence that links environmental noise and specific health effects, including cardiovascular disease, cognitive impairment, sleep disturbance and tinnitus [1,2]. Recent investigations approach this topic [3,4]. In fact, the concern about noise pollution among both the general public and policymakers is a growing trend. For example, the European Union's Seventh Environment Action Programme (7th EAP) aims that noise pollution will have significantly decreased in this territory by 2020 towards noise levels recommended by WHO [5]. For this purpose, strategic noise maps are proposed by the European Noise Directive [6] as an important resource to calculate the noise levels to which the population is exposed [7,8].

In this regard, the European Environmental Agency (EEA) [9] indicates that road traffic is the sound source that generates the greatest number of people exposed in Europe to sound levels above what is recommended by the European Noise Directive. In a similar way, the EEA also reports that air pollution is the most important environmental health risk in Europe [9]. The exposure of population to air pollution varies according to the air pollutant $\left(\mathrm{NO}_{x}, \mathrm{PM}, \mathrm{O}_{3}\right)$. All them are related to the increase of the incidence of many kind of diseases: cancer, cardiovascular, respiratory, etc. [10]. Among the sources of emission of polluting gases, road traffic is a great contributor to total nitrogen oxides and black carbon emissions. In addition, as it is a source with low emission heights, its polluting gases are concentrated near the surface and have a great health impacts in urban areas. 
Considering the relation of environmental noise and air pollution to road traffic, it leads to think about the development of common strategies. We will focus on presenting a review on recent researches about the joint relationship of these two types of pollution in urban environments with different types of diseases. Finally, we present a series of proposals from different authors in order to act on this serious environmental problem that affects the health of human beings.

\section{Review}

\subsection{Health Problems}

One of the problems studied is diabetes. Dzhambov [11] in 2015 carried out a systematic review and meta-analysis on the risk of type 2 diabetes due to long-term exposure to noise. People exposed to a high level of residential noise ( $(\mathrm{den}>60 \mathrm{~dB}$ vs. Lden $<60-64 \mathrm{~dB}$ ) may have a significantly higher risk (19-22\%) of developing type 2 diabetes. Exposure to noise at work ( $\operatorname{Lden}>85 \mathrm{~dB}$ versus $\mathrm{Lden}<85$ $\mathrm{dB}$ ) has not been associated with an increased risk. In the same sense, Eze et al. [12] investigated 2631 participants without diabetes in 2002 and without change of residence between 2002 and 2011. Based on data from questionnaires and biomarkers, they were identified cases of diabetes in 2011. The authors conclude that transport noise may be more relevant than Air Pollution (AP) in the development of diabetes, which can be explained by disturbances of sleep induced by noise. They found positive associations of road and aircraft noise, but not traffic-related AP, in the incidence of diabetes. However, in the work conducted by Dendup et al. [13] in 2018, it is concluded that the current evidence they find suggests a moderate contribution of the environment to the risk of development of Diabetes Mellitus type 2. The data show that higher levels of $\mathrm{NO}_{2}$, PM2.5 (particulate matter $<2.5 \mu \mathrm{m}$ in diameter), and noise are related to an increased risk of developing DM2. However, due to limited data on these characteristics, causality cannot be inferred.

Cholesterol was another studied health problem. Sørensen et al. [14] presented a study in 2015 that sought to relate exposure to traffic noise and air pollution with high cholesterol levels, given the already established relationship between these pollutants and cardiovascular diseases, although the mechanisms behind this partnership are not yet clear. The authors conclude that air pollution and possibly also traffic noise may be associated with slightly higher levels of cholesterol. However, the associations for the two exposures were difficult to separate.

The relationship between chemical and acoustic contamination and daily hospital admissions in the emergency department due to multiple sclerosis (MS) has also been studied by Carmona et al. [15]. The authors found that, although there was no association between chemical pollutants caused by traffic and MS admissions, such association was evident in the case of Leqd. This association is linear without a threshold and there is a level, higher than $67 \mathrm{dBA}$, from which this effect is more pronounced. The above results indicate that traffic noise can exacerbate MS symptoms, leading to hospital admissions due to this cause.

Finally, different studies point a relationship between cardio-vascular diseases and noise and air pollution. Just to indicate a few, we can cite the works of Cole-Hunter et al. [16] and Bilenko et al. [17]. In them, a relationship can be found between a long-term exposure to noise and air pollution and circulatory or heart problems. Greater awareness of the social burden of these risk factors can intensify the efforts needed for effective legislation that reduces air pollution and noise.

\subsection{Solutions}

There are several studies that propose different solutions to the existing problem in cities due to air pollution and noise produced by road traffic. For example, Vienneau et al. [18] investigated the association between residential green areas and adult mortality considering air pollution and exposure to transport noise. The authors have found consistent evidence that residential green areas reduce mortality risk independently of other environmental exposures. These authors suggest that the protective effect goes beyond the absence of sources of contamination. Public environmental health measures should not only aim to reduce the exposure of pollutants, but also to maintain existing residential green areas and increase them in areas where they are lacking. 
On the other hand, Mueller et al. [19] focused their study on burden of disease (BD) due to exposures affected by urban planning and transportation. The findings made by the authors suggest that: (1) the reduction of road traffic together with the promotion of active transport and (2) the provision of green infrastructure would result in a considerable avoided BD and substantial savings for the public health system, since these measures can provide mitigation of noise, air pollution and heat, as well as opportunities for the promotion of physical activity (PA).

Perez-Prada and Monzon [20] studied the plan launched by the Madrid City Council to redesign its inner ring for taking traffic out of the city center. The implementation of the new speed limit policy produced a reduction of $14.4 \%$ and $16.4 \%$ in $\mathrm{CO}_{2}$ and $\mathrm{NO}_{x}$ emissions, respectively, while the overall travel time remains practically constant and the saturation rate decreases slightly. Although this work has not studied the impact of reducing the speed on the environmental noise levels in the area, taking into account the direct relationship between the speed at which vehicles circulate with the level of sound pressure generated by these, it would be expected that the measure proposed in [21] would also suppose a reduction of the noise pollution levels near the Madrid ring road. On the other hand, Hamidi and Kamankesh [22] propose a multi-agent system for road traffic management based on swarm intelligence. The objective is to increase the quality of the entire road network, especially in case of congestion and traffic jams, taking into account real-time traffic information and the travel time of drivers to reach their destinations. With the proposed method, a hierarchical multi-agent architecture performs a grouping of cars and vehicles on the road according to the geographical distribution. In other works, reference semaphores are taken into account with the variable program green and red to improve the management of the road network.

To conclude this section, the work of Nieuwenhuijsen [23] places cities in a broader context and establishes links between urban planning and transport, the environment and health. In this work, multiple environmental exposures are considered identifying common determinants and linking the built environment, environmental concentrations, personal behavior and exposures and health. It also presents the state of the art on the health effects of important environmental exposures in cities and provides a framework for linking science and policy. Nieuwenhuijsen concludes that the city of the future must be a green, social, active and healthy city.

\section{Conclusions}

Recent work continues to highlight the impact on public health of noise and air pollution generated by road traffic in cities. Taking into account the relationship between both pollutants, it leads to think about the development of common strategies. Measures of action related to road traffic management (volume, speed, etc.) and urban planning (increase of green areas, urban design, etc.) are shown up to now as the most effective solutions.

Author Contributions: All the authors contributed equally to the design, implementation and writing of the manuscript.

Acknowledgments: The authors wish to thank the funded project TRA2015-70487-R (MINECO/FEDER, UE) and the Government of Extremadura, the Regional Ministry of Economy, Trade and Innovation (GR10175), the European Social Fund, the European Regional Development Fund (ERDF). This work was also partially supported by the Chilean National Commission for Scientific and Technological Research (CONICYT) through the project FONDECYT No. 1180547. G. Rey-Gozalo was supported by Juan de la Cierva-Incorporación contract from the Spanish Ministry of Economy, Industry and Competitiveness (IJCI-2016-28923).

Conflicts of Interest: The authors declare no conflict of interest.

\section{References}

1. WHO (World Health Organization). Burden of Disease from Environmental Noise; WHO: Bonn, Germany, 2011.

2. WHO (World Health Organization). Night Noise Guidelines for Europe; WHO: Copenhagen, Denmark, 2009. 
3. Münzel, T.; Sørensen, M.; Schmidt, F.; Schmidt, E.; Steven, S.; Kröller-Schön, S.; Daiber, A. The Adverse Effects of Environmental Noise Exposure on Oxidative Stress and Cardiovascular Risk. Antioxid. Redox Signal. 2018, 20, 873-908, doi:10.1089/ars.2017.7118.

4. Azuma, K.; Uchiyama, I. Association between environmental noise and subjective symptoms related to cardiovascular diseases among elderly individuals in Japan. PLoS ONE 2017, 12, e0188236, doi:10.1371/journal.pone.0188236.

5. Managing Exposure to Noise in Europe; European Environment Agency: Copenhagen, Denmark, 2017.

6. EC (European Commission). Directive 2002/49/EC Relating to the Assessment and Management of Environmental Noise; Office Journal Euro Commun L 189; European Commission: Brussels, Belgium, 2002; pp. 12-26.

7. Barrigón Morillas, J.M.; Montes González, D.; Rey Gozalo, G. A review of the measurement procedure of the ISO 1996 standard. Relationship with the European Noise Directive. Sci. Total Environ. 2016, 565, 595606, doi:10.1016/j.scitotenv.2016.04.207.

8. Montes González, D.; Barrigón Morillas, J.M.; Godinho, L.; Amado-Mendes, P. Acoustic screening effect on building façades due to parking lines in urban environments. Effects in noise mapping. Appl. Acoust. 2018, 130, 1-14, doi:10.1016/j.apacoust.2017.08.023.

9. EEA (European Environment Agency). Noise in Europe 2014; EEA: Luxembourg, 2014.

10. WHO (World Health Organization). WHO Expert Consultation: Available Evidence for the Future Update of the WHO Global Air Quality Guidelines (AQGs); WHO Regional Office for Europe: Copenhagen, Denmark, 2016.

11. Dzhambov, A.M. Long-term noise exposure and the risk for type 2 diabetes: A metaanalysis. Noise Health 2015, 17, 23-33, doi:10.4103/1463-1741.149571.

12. Eze, I.C.; Foraster, M.; Schaffner, E.; Vienneau, D.; Héritier, H.; Rudzik, F.; Thiesse, L.; Pieren, R.; Imboden, M.; von Eckardstein, A.; et al. Long-term exposure to transportation noise and air pollution in relation to incident diabetes in the SAPALDIA study. Int. J. Epidemiol. 2017, 46, 1115-1125, doi:10.1093/ije/dyx020.

13. Dendup, T.; Feng, X.; Clingan, S.; Astell-Burt, T. Environmental Risk Factors for Developing Type 2 Diabetes Mellitus: A Systematic Review. Int. J. Environ. Res. Public Health 2018, 15, 78, doi:10.3390/ijerph15010078.

14. Sørensen, M.; Hjortebjerg, D.; Eriksen, K.T.; Ketzel, M.; Tjønneland, A.; Overvad, K.; Raaschou-Nielsen, O. Exposure to long-term air pollution and road traffic noise in relation to cholesterol: A cross-sectional study. Environ. Int. 2015, 85, 238-243, doi:10.1016/j.envint.2015.09.021.

15. Carmona, R.; Linares, C.; Recio, A.; Ortiz, C.; Díaz, J. Emergency multiple sclerosis hospital admissions attributable to chemical and acoustic pollution: Madrid (Spain), 2001-2009. Sci. Total Environ. 2018, 612, 111-118, doi:10.1016/j.scitotenv.2017.08.243.

16. Cole-Hunter, T.; de Nazelle, A.; Donaire-Gonzalez, D.; Kubesch, N.; Carrasco-Turigas, G.; Matt, F.; Foraster, M.; Martínez, T.; Ambros, A.; Cirach, M.; et al. Estimated effects of air pollution and space-time-activity on cardiopulmonary outcomes in healthy adults: A repeated measures study. Environ. Int. 2018, 111, 247-259, doi:10.1016/j.envint.2017.11.024.

17. Bilenko, N.; Rossem, L.V.; Brunekreef, B.; Beelen, R.; Eeftens, M.; Hoek, G.; Houthuijs, D.; De Jongste, J.C.; Kempen, E.V.; Koppelman, G.H.; et al. Traffic-related air pollution and noise and children's blood pressure: Results from the PIAMA birth cohort study. Eur. J. Prev. Cardiol. 2015, 22, 4-12, doi:10.1177/2047487313505821.

18. Vienneau, D.; de Hoogh, K.; Faeh, D.; Kaufmann, M.; Wunderli, J.M.; Röösli, M.; SNC Study Group. More than clean air and tranquillity: Residential green is independently associated with decreasing mortality. Environ. Int. 2017, 108, 176-184, doi:10.1016/j.envint.2017.08.012.

19. Mueller, N.; Rojas-Rueda, D.; Basagaña, X.; Cirach, M.; Cole-Hunter, T.; Dadvand, P.; Donaire-Gonzalez, D.; Foraster, M.; Gascon, M.; Martínez, D.; et al. Health impacts related to urban and transport planning: A burden of disease assessment. Environ. Int. 2017, 107, 243-257, doi:10.1016/j.envint.2017.07.020.

20. Perez-Prada, F.; Monzon, A. Ex-post environmental and traffic assessment of a speed reduction strategy in Madrid's inner ring-road. J. Transp. Geogr. 2017, 58, 256-268, doi:10.1016/j.jtrangeo.2016.12.018.

21. Donavan, P.; Schumacher, R. Exterior Noise of Vehicles-Traffic Noise Prediction and Control. In Handbook of Noise and Vibration Control; John Wiley \& Sons: Hoboken, NJ, USA, 2007; Chapter 120. 
22. Hamidi, H.; Kamankesh, A. An Approach to Intelligent Traffic Management System Using a Multi-agent System. Int. J. ITS Res. 2018, 16, 112-124, doi:10.1007/s13177-017-0142-6.

23. Nieuwenhuijsen, M.J. Urban and transport planning, environmental exposures and health-new concepts, methods and tools to improve health in cities. Environ. Health 2016, 15, 38, 161-171, doi:10.1186/s12940-0160108-1.

(C) 2018 by the authors. Licensee MDPI, Basel, Switzerland. This article is an open access article distributed under the terms and conditions of the Creative Commons Attribution (CC BY) license (http://creativecommons.org/licenses/by/4.0/). 